\title{
Fair Labor Standard Act Mandate: How Do Higher Education Human Resource Departments React?
}

\author{
Matthew VanSchenkhof ${ }^{1}$, Matthew Houseworth ${ }^{2} \&$ Scott Smith $^{3}$ \\ ${ }^{1}$ Assistant Professor of Management and Hospitality, Montana State University, Montana, USA \\ ${ }^{2}$ Assistant Professor in the Department of Management, University of Central Missouri, Missouri, USA \\ ${ }^{3}$ Professor of Marketing, University of Central Missouri, Missouri, USA \\ Correspondence: Scott Smith, Professor of Marketing, University of Central Missouri, Missouri, USA.
}

Received: June 21, 2017

Accepted: July 12, 2017

Online Published: July 18, 2017

doi:10.5430/ijba.v8n5p36

URL: https://doi.org/10.5430/ijba.v8n5p36

\begin{abstract}
Mandates from the United States government may create drastic changes in the university landscape. The Fair Labor Standard Act (FLSA) Mandate that was expected to go into effect in December of 2016 provided a means to understand how required changes impact the human resource (HR) departments within institutions. This paper addresses the primary concerns of institutional human resource departments as the FLSA mandate required status changes for up to $15 \%$ of the campus workforce. Analysis of forecasted issues with employee engagement generated central issues regarding ability to communicate with constituents, resources available to HR departments, faculty and staff morale, compensation fairness, while not concentrating on employee engagement.
\end{abstract}

Keywords: human resources, employee engagement, compensation, employee morale

\section{Introduction to the Situation}

Human resource departments within higher education find themselves adopting new policies based on changing labor laws or labor mandates on a regular basis. This paper outlines predominant issues faced by human resource managers across twelve academic institutions. Twelve structured telephone interviews following McCraken's (1988) process of analysis were conducted focused on how one mandate in particular may impact employee engagement. Beyond employee engagement concerns, the research found human resource departments very concerned with how to manage: communication with their constituency; compensation concerns; morale across employee status; and limited departmental resources.

December 1, 2016 marked the date that the mandated changes to the Fair Labor Standards Act (FLSA) was supposed to go into effect requiring exempt white collar employees to receive compensation of at least $\$ 47,476$ per year. This was a 200 percent increase over the previous requirement and created dilemmas for human resource professionals across industries throughout the United States. In effect, specific issues related to low to mid-level manager workplace engagement and satisfaction were of concern because they were the effected individuals. This research analyzed human resource manager concerns with implementation of the FLSA mandate and issues related to pay and/or how benefits may impact employee engagement within an organization. Further, methods for addressing negative issues forecasted by these changes to manager pay were discussed.

This paper presents evidence of human resource director's concerns of impacts to employee engagement created by the implementation of the Fair Labor Standards Act (FLSA) Mandate. No previous studies provide guidance or reactions from organizations to previous FLSA mandates beyond legal analysis. Literature, at present, does not provide interpretation beyond informal printed and digital commentary. The uniqueness of the situation created by implementation of this mandate created a void that this paper's authors were attempting to fill. Direct concerns were expected with how effected lower and mid-level managers would react to changes in pay and benefit structure based on a reclassification required by the new threshold.

This study attempts to answer the following research questions:

QUESTION 1: How do human resource managers in higher education affect employee engagement within their organization? 
QUESTION 2: What do human resource managers in higher education believe are the greatest threats to employee engagement due to mandates impacting pay and/or benefits?

QUESTION 3: How does a requisite mandate such as FLSA specifically impact higher education?

QUESTION 4: How do higher education human resource managers prepare for mandates?

QUESTION 5: How does the anticipated FLSA mandate positively impact human resource departments in higher education?

\section{The Fair Labor Standards Act}

In 2014, President Barack Obama proposed rule changes as way to update the regulations associated with protecting white collar worker's minimum salary threshold under the Fair Labor Standards Act (FLSA) (Gillis, Ellis, \& Baker Inc., 2015). In May of 2016, the United States Department of Labor (DOL) issued a final rule to amend the rules associated with "white collar exemptions" outlined in the FLSA. The final ruling is expected to impact more than 4 million workers across the United States. Further, the ruling creates required changes by higher education human resource managers in determining how the mandate should be implemented across their institutions.

The FLSA rule is expected to impact lower and mid-level managers and employees with the white-collar exemption status (Radelet, 2015). This is of concern to human resource managers within higher education, as negatively perceived changes to pay and benefits are likely to impact the organizational engagement of affected parties (Gardner, 2016). Attempting to mediate and minimize employee engagement issues brought about by the mandated changes has not been previously researched, particularly when it impacts such a large portion of the workforce directly responsible for leading hourly employees.

The Fair Labor Standards Act (FLSA) determines the minimum wage amounts and overtime pay standards as well as provides the U.S. Department of Labor's (DOL) Wage \& Hour Division the ability gather data and amend exempt status regulations (US Legal, n.d.). The FLSA has been amended and updated in various ways since its inception in 1938. The current status update proposed changes to the named "white collar" exemptions governing exempt and non-exempt employee compensation standards.

According to Chamberlain, Kaufman and Jones (2007), jobs are designated as either "exempt" or "non-exempt." The difference between the two designations is rather simple. The non-exempt employee, typically compensated on an hourly basis, is entitled to overtime pay once the employee has exceeded 40 hours for the work week. In contrast, exempt employees, typically compensated through an annual salary, are not eligible for overtime pay regardless of the length of the employee's work week (Chamberlain, Kaufman \& Jones, 2007). The updated ruling that was expected to go into effect December 1, 2016 stated:

(a) The exempt salary threshold level will be increased from $\$ 455.00$ per week to $\$ 913.00$, for a total of $\$ 47,476$ per year $\left(40^{\text {th }}\right.$ percentile of weekly earnings for full-time salaried workers).

(b) Automatically update annually the standard salary level through the $40^{\text {th }}$ percentile level of weekly earnings of full-time salaried workers or by the Consumer Price Index for All Urban Consumers (CPI-U). The first update would occur in 2020.

(c) Salaries for Highly Compensated Employees (HCE's) will have an annualized value of the $90^{\text {th }}$ percentile of weekly earnings of full-time salaried workers and will be raised from $\$ 100,000$ to $\$ 134,148$ annually.

(d) 10 percent of the new salary threshold for Non-Highly Compensated Employees (HCE's) can be met through non-discretionary bonuses, incentive pay, or commissions, as long as the payments are made on a quarterly basis.

In November of 2016 the mandate was temporarily halted via a federal court in Texas. At this juncture, it is uncertain whether the new rule will be enacted as currently written or not.

\subsection{FLSA in Higher Education}

Gardner (2016), in discussing the California State University system via Marc Mootchnik, stated that the FLSA mandate is predicted to impact $20 \%$, or 8,000 system employees. It was expected that large numbers of university employees would be either reclassified or work roles impacted in some form (Wexler, 2016). It was projected that 1,400 employees at Indiana University, 1,034 employees at Kansas State University, and 2,700 employees at the University of Iowa would be reclassified (Wexler, 2016).

The major concern is that a significant portion of non-teaching employees work non-traditional hours with schedules that fluctuate periodically throughout the year (Gardner, 2016). This includes admissions representatives who travel 
during the recruitment cycle in the early fall and early spring often working $80+$ hours per week. Athletic and academic coaches put in long hours during their respective seasons or with travel for recruitment. Further, research postdocs (teaching postdocs are not affected) typically maintain schedules that do not conform to the typical 40-hour work week (Gardner, 2016). Those employees whose primary responsibility was teaching would not be affected because they would not fall within the FLSA exempt status.

Unfortunately the reality is that universities do not have the funding to appropriately comply with the new rules (Gardner, 2016; Wexler, 2016). The result of this amendment requires universities to select from multiple options. The two primary options are: (1) reclassify the employee to non-exempt (hourly) and pay an hourly wage equitable to the same amount they make; or (2) maintain exempt status and increase the salary to the new threshold.

The mandate is expected to impact all universities, whether public or private, but effects are expected to be more challenging for small private institutions and those located outside of metropolitan areas (Gardner, 2016). Traditionally, salaries are lower and these institutions are more likely to already be economically weaker.

\section{Employee Engagement}

Saks (2006) clearly states that employee engagement: "is the degree to which an individual is attentive and absorbed in the performance of their roles" (p. 602). Fundamentally, engagement is a measure within an employee's formal role and is not voluntary or citizenship behavior. Additionally, Kahn (1990) is seen as the first to address employee engagement as how an individual perceives themselves within their task behaviors and how this perception imparts their performances within that role.

Robison (2012) identifies employee engagement as it applies to three types of employees: 1) those who are actively disengaged and those sabotage the work of others, 2) those who are not engaged, and 3) those who are engaged. Robison asserts that engaged employees believe they are directly connected to their organization and that they are able to act innovatively and help their organization to mature in a positive direction.

Literature discusses many items that impact employee engagement. Of these, employee engagement has been found to be significantly correlated with rewards (including pay) and recognition (Saks, 2006). We view the incoming FLSA mandate as potentially affecting three areas influenced by employee engagement: (1) pay and prestige of position as a key driver; (2) productivity impacts related to pay; and (3) influences controlled by received benefits, hours, and the employee-employer relationship.

\subsection{Pay and Prestige of Position}

While the effect pay has on motivation has been previously discussed, Rynes, Herhart, \& Minette (2004) emphasize that much of the literature discussing impacts, as associated with employee motivation, tends to be focused on the environment surrounding a position versus pay. Additionally, they assert that pay has traditionally been underreported as to the strength of the impact it has on employee motivation. Rynes, Herhart, \& Minette (2004) maintain that practitioner journals will often state results that do not correlate with the actual effect pay has on employee motivation.

Locke, Feren, McCaleb, Shaw, and Denny, in their 1980 presentation state that pay had the strongest impact on employee productivity. They found that pay incentives increased productivity an average of $30 \%$ while job enrichment programs increased productivity from $9-17 \%$ on average. Locke, et. al. (1980) concluded: "Money is the crucial incentive ... no other incentive or motivational technique comes even close to money with respect to its instrumental value" (p. 379).

Guzzo, Jette, and Katzell, (1985) measured monetary incentives versus other motivational programs and found that financial incentives, by far, led to increases in productivity. They found pay had four times more influence versus attempting to make work more interesting. Judiesch (1994), in reporting on a meta-analysis of pay incentives, found that studies in actual organizations indicated an average increase in productivity by $48.8 \%$.

This is an indication that employees who feel undervalued or who may be negatively affected by mandated changes are likely to have decreases in productivity while those that are positively affected will deliver better productivity.

\subsection{Productivity Impacts}

It is readily acknowledged that pay is used as a mechanism to influence an employee's behavior, hopefully in a positive manner. Gagne \& Forest (2011) propose that the amount of pay, in a financial value, is directly linked with an employee's satisfaction of needs and, hence, employee engagement. Kuvaas (2006) finds that higher intrinsic work motivation is associated with affective commitment and better performance. 
Harter, Schmidt, and Hayes (2002) discuss that employee engagement showed generalizability across organizations in several factors including productivity. Rynes, Herhart, \& Minette (2004) claim that pay is a high motivational factor and can impact employee engagement through productivity measures. Harter, Schmidt, Hayes (2002) also find that sub-units within organizations that are found to have engaged employees outperformed disengaged employee sub-units with a $103 \%$ higher success rate.

It has been previously discussed that pay's effect as a motivator has some dependence on situational factors (Locke, et. al., 1980; and Rynes, et. al., 2004) such as those being faced by the FLSA mandate. Decisions whether to increase to the new threshold or change status should be expected to lead to changes in productivity impacts.

Employees are more likely to repay their organization when they receive appropriate financial resources (Barrus, Costello, Beaman, \&Westover, 2016; Saks, 2006) and this is often demonstrated in productivity measures or management of other productivity measures.

\subsection{Benefits, Hours, and the Employee-Employer Relationship}

Saks (2006), in discussing Kahn's 1990 work, contends that adequate available resources, such as pay, impacted an employee's psychological availability. Moreover, Saks (2006) finds employees will repay their organizations with varying levels of engagement and that compensation is one of those resources used to determine engagement.

Higher base pay has been found to be correlated with better performance and affective commitment (Gagne \& Forest, 2011). The amount received as base pay is often recognized as a measure of competence by the employee within their workplace relationship. Receiving what is perceived to be an adequate base pay allows for the employee to focus on "higher order needs" being met in the workplace (Gagne \& Forest, 2011). This may be associated with the tipping point where other workplace interventions have greater effect on employee performance.

When organizations do not fulfill the monetary resource requirements, the employee is likely to disengage from their responsibilities within their roles (Saks, 2006). In the case of the FLSA Mandate an employee, changing from salary to hourly and is now required to work overtime to make the same amount in pay, is likely to withdraw from their role. "Thus, the amount of cognitive, emotional, and physical resources that an individual is prepared to devote in the performance of one's work roles is contingent on the economic and socioemotional resources received from the organization" (Saks, 2006, p. 603).

There may be fears from affected employees associated with any changes to their compensation status. Social Exchange Theory finds an employer who enacts the FLSA Mandate in a fair manner is likely to not impact the engagement, relationship, or reciprocity shared with the employee (Cropanzano and Mitchell, 2005).

Saks (2006) asserts that employee engagement is based on a long-term employee-employer relationship. Additionally, engaged employees demonstrate "high-quality relationship(s) with their employer" (p. 613). Hence, dramatic changes in pay based on adopting the FLSA Mandate may severely threaten that reciprocal relationship and more time may be needed to bring engagement into balance.

\section{Method}

This study employed semi-structured interviews with twelve full-time human resource directors or managers for a cross-section of four-year higher educational institutions. This method was selected as language use by participants was likely to fluctuate between institutions. Convenience sampling was utilized via contacts through the authors' university human resource manager. The research was approved via the university's institutional review board. The author's university was not included in the interviews and the human resource director who provided the sample for interviewing was not privy to the questions.

Structured telephone interviews were conducted, as telephone interviews can be a very effective and economical way of collecting data where the sample to be contacted are geographically dispersed. Telephone interviewing can be ideally suited to busy professional respondents, such as human resources managers, and timed appointments can be set up.

The human resource director emailed a form requesting participation to two organization's members on behalf of the authors. From the contact list provided, each respondent was asked if they'd be willing to answer questions about the Fair Labor Standards Act and employee engagement at their organization via a telephone call and to provide a best time to receive a phone call. Each respondent was instructed that the interview would take less than 30 minutes and all responses would be kept confidential. Informants were advised that if individual responses were to be reported, they would be coded and non-identifiable.

The development of the final instrument was based on the literature review and two exploratory interviews. While 
the interview topics were established by the authors, refining of the questions and a search for other important topics that might have been overlooked was accomplished via two exploratory interviews. Further, questions were piloted during the exploratory interviews. The exploratory interviews followed the same format as the interviews included in this study.

The established interview questions were asked of each respondent in the same order (see Appendix A). A minimum of two authors participated in each interview and a high-quality speakerphone was used to conduct the interviews. Verbal consent was secured prior to continuing with the interview and informants were made aware that their answers were being recorded but would be non-identifiable if reported. Respondents were given the option to not have the interview recorded. While the interview topics were established by the authors, refining of the questions and a search for other important topics that might have been overlooked was accomplished via two exploratory interviews, following the same format as the interviews included in this study. The interview questions established through this exploratory interview process were asked of each respondent in the same order (see Appendix A). Questions pertained to employee engagement issues at his/her organization and upcoming FLSA exemption status changes. Limited probing was conducted to clarify responses to questions and to ensure valid responses were recorded by the authors. Each interview was recorded and notes were taken by the attending authors. All notes and recordings were made available to the investigators.

At the conclusion of the phone interview, researchers clarified notes taken during the interview individually, discussed responses for consistency and to illuminate any variations in response interpretation. Recorded responses were replayed and discussed further.

Following the interview, recorded responses were transcribed. With the interviews computerized, data was coded and summarized and patterns were identified using frequencies of words to provide some guidance for the analysis. Utilizing the WEFT QDA data solutions free, open-source software, word counts and thematic frequencies were identified as consistent in the data.

Respondents were predominantly male (7) and this ratio deviates from the human resource industry average, where 70 percent of human resource managers are female (Young Entrepreneur Council, 2012). On average, these professionals had been in their current role for approximately three years, with a range of 6 months to 25 years. The number of university employees that each human resource manager/director oversaw was between 785 and approximately 16,000 . Ten of the respondents had fewer than 2,800 employees.

A cross-section of the interviewed universities included (enrollment): 4 small private $(<5,000) ; 2$ small public $(<5,000)$; 4 public medium $(<17,000)$; and two public large $(>25,000)$. Universities were predominantly located in the Midwest (10), one in the Northeast, and one in the West. Size of the human resource departments ranged from 1 to 28 , with the large institutions having more than 20 human resource professionals on staff. The four private small institutions had one or two full-time human resource professionals within their respective department.

\section{Thematic Analysis}

In semi-structured interviews, a series of initial open-ended questions are presented, accompanied by probing queries for more detailed information, are asked of each respondent. Following McCraken's (1988) process of analysis, each interview transcript was reviewed twice, once for content understanding and a second for noting interesting observations. Observations are developed into preliminary descriptive and interpretive categories. Patterns of themes are then pulled the categories are pulled from the categories and prominent themes are identified.

Five themes emerged from the interviews: (1) compensation requirements were significant and created a type of "comp-ageddon," or devastating situation with compensation; (2) potential issues in the creation of a second-class citizen; (3) HR departments had few developed communication channels; (4) institutions either have access to resources or do not; and (5) employee engagement, overall, was not a priority.

\section{1 "Comp-ageddon"}

While the strategies for handling the upcoming mandated changes in compensation were varied, general agreement indicated that this was a very significant change to deal with quickly. One particular interviewee dubbed this regulation "Comp-ageddon". There was general sentiment that some policy change was needed, and that employee classifications and wage adjustments were very necessary in some cases. But the perceived drastic level of change seemed ill-conceived to most of our informants. Quotes such as "too much, too fast", "rip the Band-Aid off", "not phased in", and "overdue but poorly done" were heard throughout all of the interviews. One informant felt that they were being asked to "enforce irrational compensation laws" discussing both the speed of change and the amount associated with the new regulations. 
Several of the schools saw big challenges with implementation of the regulatory change. And while others seemed better prepared to deal with the compensation changes, all interviewed were apprehensive about parts of their compensation models. At the time of the interviews, (August and September of 2016) only two had completed the process of examining employee classifications. The remaining institutions were in process or waiting on legal examination of their results. Some of the classifications were difficult under the new FLSA guidelines.

Several of our informants indicated that they needed to purchase or update "time clock" software programs equipped for these changes. They found that for many positions, including athletic trainers, coaches, recruiters, and others that the necessary software would need to be accessible on employee's phones, as these employees were often away from the office or a computer while working. Others were concerned with training formerly exempt employees on the process for keeping track of hours worked.

Half of those interviewed were faced with non-equitable benefits between exempt and non-exempt staff. They discussed compensation components outside of wages or salary. For example, accruing vacation and sick time was a compensation area that was affected for some of the institutions. Reclassifying employees changed the vacation accrual for those employees. One institution we spoke to had decided to allow those employees moving from exempt to non-exempt to keep the vacation accrual amounts they had with their previous classifications.

Strategies like this vacation policy seem reasonable for a newly reclassified employee, but place the institution in an awkward position with regards to other employees in the same classification. Compensation situations and decisions like this appeared to be challenging for those to whom we spoke.

\subsection{Morale and the Second Class Citizen}

In addition to the compensation concerns, morale was another concern for the human resource professionals we spoke to. Most of these individuals felt very positively about the cultural climate of their organizations. A strong sense of apprehension about the change in morale was indicated by six of the institutions, due primarily from changes in classifications. There was a perception, that for employees, the idea of moving from exempt to non-exempt would be a demotion, even if the amount of wages/salary remained equal. The notion that "I'm a clock puncher now" would be a demeaning change to those formerly in the exempt category and that exempt employees might view the new categorization as being a "second class citizen". There was obvious status and prestige with exempt status. One informant we spoke to speculated that employees changing from exempt to non-exempt would be willing to take less money to keep their classifications.

I think, overall, our employees would feel that it's worth about \$5,000 just to keep their exempt status.

Three HR managers were concerned with the culture within departments and among co-workers when at least one peer, potentially more, would remain exempt and others would become non-exempt hourly staff. The perception of self-value versus job responsibilities was thought to be at risk and potentially toxic.

When half of a department gets to keep their status with an un-earned artificial raise in pay, there is probably a change in pride and trust in the university and probably anger towards others they work with. We're trying to figure out how we minimize this but we know just explaining why won't impact their perception.

Other potential morale issues were found to be related to the freedom that exempt status allows for employees in the performance of their tasks. One informant believed that an "an ability to manage their own time is lost" and "the employee has less control to get their job done." Inversely, additional responsibility was created for supervisory staff who "now have to oversee hourly staff" and determine "how to hold them responsible". These changes were feared to generate "limited power" situations that "can't fix supervisory issues on their own".

Finally, several institutions found that they would need to purchase or replace existing payroll software to accommodate the FLSA changes. The change in processing hours worked or even the change in supervisor examination and validation of employee work time could also carry a negative reaction.

\subsection{Communication: We Needed Change...Because They Said So}

One of the interesting things we found through the interviews was the varied consideration and plans for communicating the institutions strategy for implementing changes. All but one institution had received very few questions from those that were potentially affected. Instead, questions directed toward human resources were predominantly from the administration and outside legal counsel. One institution created and maintained a database of all questions they had been asked and more than half were from those who had potentially reclassified employees reporting to them and how to move forward. Formal communication channels to the university communities had only 
taken place in two of those interviewed. One particular individual had begun a newsletter addressing classification, compensation, and other areas affected as they were handled by the institution. She called the newsletter the "Compensation Times". A few of the human resource professionals interviewed seemed to have already begun an open communication line to administrators about the FLSA mandated changes but these were typically informal.

Every respondent indicated a strong desire to be as transparent as possible throughout the process. This included the decision-making associated with how status was determined. However, some institutions were still mired in discussions about classification or other issues. Hence, information that was available for communication to the institution was very limited.

Overall, the sentiment from most respondents indicated a lack of communication channels between the human resources departments and the faculty and staff. The FLSA mandate, beyond the status evaluations and changes, caused HR managers to understand there was an inherent inability to effectively communicate to their constituency. This was realized with two interview questions centered on preparation for changes and positive outcomes from the FLSA process.

Some were having difficulty in coming up with a clear strategy on not only how, but who to communicate with specifically. General sentiment was that it was difficult or there were no sound methods to reach out to the larger community.

We need to increase our ability to communicate to all of those what is happening and why. We need to do it in a way that they will listen and understand. How do we do that effectively? We know we'll talk to those impacted in one-on-one but are looking at better big picture ideas.

Better two-way dialogue was expected based on whatever the communication process would end up being. HR Departments believed that, if handled appropriately and fairly, their constituency would be more willing to share other issues from within the community.

Regardless of the process used, all interviewed felt they would be much more confident in how to communicate with the university community because of the issues associated with implementation of the FLSA Mandate. More than half stated that a positive aspect associated with the rollout was the development of more open communication methods that more clearly reach the intended audience.

\subsection{Have versus Have Not}

One of the prominent differences that appeared in the interview data existed between institutions that we have categorized as more established based on longevity as an institution, fiscal stability, and human resource procedures. Those educational institutions that "have" existed for a long time and "have" more stability, responded differently to questions regarding effects of the proposed FLSA changes to their institutions. Factors such as size of staff, access to resources, and having the ear of the administration seemed to play a large role in the sentiment of our interviewees.

With regard to preparations for the mandated change, established, or "have", institutions were more confident in the process they were developing or had in place to deal with the changes. They also tended to have more staff working on the issues around the mandated changes. Those institutions with smaller or a single person addressing the FLSA issues seemed less confident and more challenged by the changes.

The "have" institutions felt that they were allowed to set strategy and prepare policy changes at their institutions. One particular respondent from an established institution described the changes they made to their policy as "not very difficult, we already had a seat at the table". The less established institutions, or "have nots" did express concerns for getting new policies in place at their schools. Further, three of the "have not" responses indicated that there had been very little communication with administrators about the changes, and that many administrators were unaware of the pending regulatory changes until they were approached by human resource professionals at the institution. One response humorously detailed

I am doing my best to make it as simple as possible. I'm trying not to inconvenience them (affected). I asked my bosses (administration) on my direction and they were completely unaware. They just said OK and keep moving forward.

"Have" institutions were also more likely to have plans in place for communication and funding policy initiatives regarding the FLSA changes. The perspective of these professionals could be viewed as more progressive. All respondents saw this as mandated and, to some degree, as a needed change in the regulation. The "Haves", the two large institutions, felt the mandate was manageable while the medium and smaller institutions, the "have nots", viewed the pending changes more critically. 


\subsection{Employee Engagement}

Across all interviews, all but one human resource manager believe employee engagement to be synonymous with organization citizenship behavior (OCB). Employee engagement was equated with an individual going above and beyond, "willing to put extra effort for the team", or completely unsure of what it was: "Engagement is one of those topics we're trying to figure out". One director stated that employee engagement is in the role and associated with "enthusiasm and attitude toward their position and the organization.

Every participant discussed key drivers associated with employee engagement as it applies to benefits including health programs, access to resources, benefits including access to free or reduced cost university athletics and programming. Half of the respondents indicated that employee engagement needs to be personalized and with three directors discussing how their institution attempts to make the cost associated with their benefit package transparent. Methods to do so included a biweekly newsletter associated with benefits and the upcoming FLSA changes, creation of a "career tool kit" for each employee, and a benefits "report card" for each employee.

\section{Conclusion}

This paper explored the primary concerns of academic institutional human resource departments as they pertained to the proposed FLSA mandate. Information collected from professionals involved in the efforts to handle the rollout of the mandate yielded perceived issues with employee compensation fairness, morale, communication difficulties and resource availability for HR departments planning on or in the process of reacting to the mandate. Discrepancies existed in regards to these issues between those larger and more established institutions and those that did not have the longevity, size or fiscal stability. Yet, there were commonalities in concerns about the new FLSA guidelines.

Overall sentiment depicted the mandate as a substantial change in practice. While there was common opinion that some change was needed, the perceived policy change was viewed as too drastic. Implementation was going to be complicated for many of the institutions, whether that difficulty resulted from budgetary constraints, faculty and staff training on policy changes, or changes to record keeping processes or software.

In addition to changes in compensation and policy, this study has identified that morale was a focus of concern for those interviewed. The perception of a change in classification would be perceived as a demotion for those moving into the non-exempt classification. Despite the fact that some employees would move up in classification, this did not offset the apprehension of the HR professional we interviewed.

An interesting finding in this study was the critical need for communication in this policy change process, but there were varied levels of preparedness and different strategies for implementing a communication flow to faculty and staff, as well as administration. While most of the communication stream concerning changes was upwards, toward concerned administrators, formal communication channels were not prevalent. While transparency in the process was strongly desired, a clear strategy to ensure this was not visible at most of the institutions.

This study provides critical factors to consider for a large-scale change and implementation in HR policy due to sweeping regulatory changes. The ability to communicate changes with constituents, manage resources available for implementation to HR employees, care for morale and cultural repercussions, and demonstrate compensation fairness are fundamental starting points for handling this type of regulatory shift. In the face of change, HR professionals and departments should ensure that a transparent communication flow is established, taking into account the organizational culture and trying to preserve it. Being upfront about the reasons for the change, what the change will look like in the organization, and why those change decisions were made should be an imperative for an organization facing similar situations to the FLSA changes.

\section{References}

Barrus, A., Costello, S., Beaman, G., \& Westover, J.H. (2016). Exploring Comparative Employee Engagement: Six Case Studies of High-performing Organizations. Management Education: An International Journal, 16(1), $1-12$.

Chamberlain, Kaufman, \& Jones. (2007). FSLA coverage [PDF document]. Retrieved from http://www.flsa.com/pdf/coverage.pdf

Cropanzano, R., \& Mitchell, M. S. (2005). Social exchange theory: An interdisciplinary review. Journal of Management, 31(6), 874-900. https://doi.org/10.1177/0149206305279602

Gagné, M., \& Forest, J. (2011). The study of compensation systems through the lens of self-determination theory: Reconciling 35 years of debate. CIRANO-Scientific Publication (2011s-54). 
Gardner, L. (2016, September 2). Colleges brace for impact of overtime rule. Chronicle of Higher Education. Retrieved from http://www.chronicle.com/article/Colleges-Brace-for-Impact-of/237583?

Gillis, E., \& Baker, Inc. (2015). DOL proposes changes to FLSA white collar exemption rules [PDF document]. Compliance Bulletin. Retrieved from http://www.gnof.org/wp-content/uploads/2015/10/DOL-Proposes-Changes-to-FLSA-White-Collar-ExemptionRules-Handout.pdf

Guzzo, R.A., Jette, R.D., \& Katzell, R. A. (1985). The effects of psychologically based intervention programs on worker productivity: A meta-analysis. Personnel Psychology, 38(2), 275-291.

Harter, J. K., Schmidt, F. L., \& Hayes, T. L. (2002). Business-unit-level relationship between employee satisfaction, employee engagement, and business outcomes: A meta-analysis. Journal of Applied Psychology, 87(2), 268-279. https://doi.org/10.1037//0021-9010.87.2.268

Judiesch, M. K. (1994). The effects of incentive compensation systems on productivity, individual differences in output variability and selection utility. Unpublished doctoral dissertation, University of Iowa.

Kahn, W. A. (1990). Psychological conditions of personal engagement and disengagement at work. The Academy of Management Journal, 33(4), 692-724.

Kuvaas, B. (2006). Work performance, affective commitment, and work motivation: The roles of pay adminstration and pay level. Journal of Organizational Behavior, 27(3), 365-385. https://doi.org/10.1002/job.37

Locke, E. A., Feren, D. B., McCaleb, K. N., \& Denny, A. T. (1980). The related effectiveness of four methods of motivating employee performance. In K. D. Duncan, M. M. Gruneberg, \& D. Wallis (Eds), Proceedings of an international conference on changes in the nature and quality of working life (pp. 363-388). Great Britain: John Wiley \& Sons Ltd.

Radelet, F. (2015). The new FLSA regulations: What changed, what didn't, what's next for employers. Wage \& Hour Insights-Guidance \& Solutions. Retrieved from http://www.wagehourinsights.com/exemptions/the-new-flsa-regulations-what-changed-what-didnt-whats-next-f or-employers/

Robison, J. (2012, Dec. 18). For employee well-being, engagement trumps time off. Gallup Business Journal. Retrieved

from http://www.gallup.com/businessjournal/159374/employee-wellbeing-engagement-trumps-time-off.aspx

Rynes, S. L., Herhart, G., \& Minette, K. A. (2004). The importance of pay in employee motivation: Discrepancies between what people say and what they do. Human Resource Management, 43(4), 381-394. https://doi.org/10.1002/hrm.20031

Saks, A. M. (2006). Antecedents and consequences of employee engagement. Journal of Managerial Psychology, $21,600-619$.

U.S. Wage and Hour Division. (n.d.). Section 4: Overtime, continued. State and Local Government Employer's Interactive Compliance Assistance Tutorial. Retrieved from http://www.dol.gov/whd/stateandlocalgovernment/ca_tutorial/media/OT\%20Examples\%20Final.htm

US Legal. (n.d.). Wage and hour division law \& legal definition. Retrieved from http://definitions.uslegal.com/w/wage-and-hour-division/

Wexler, E. (2016, February 23). What does the Department of Labor's overtime rule mean for higher education? Inside Higher $E d$. Retrieved from https://www.insidehighered.com

Young Entrepreneur Council. (2012, July 11). Why human resources isn't just for women anymore. Forbes. Retrieved

from https://www.forbes.com/sites/theyec/2012/07/11/why-human-resources-isnt-just-for-women-anymore/\#53425eb 35342 


\section{Appendix A}

Interview Questions:

1. What comes to mind when I say employee engagement?

2. How do you manage employee engagement?

a. How do you manage employee engagement through pay?

3. Outside of your own experiences, how do other HR managers to discuss employee engagement?

4. What comes to mind when I say FLSA exemptions status change?

5. How do the upcoming FLSA increases specifically impact your industry?

6. How are you preparing for these changes?

7. What do you believe are the greatest threats to employee engagement due to FLSA changes?

a. How are you planning on minimizing these disruptions?

b. What do you believe are the perceptions of impacted employees?

8. What questions have you been asked by employees about FLSA?

9. Can you provide other examples of mandated change you have experienced due to regulatory shifts?

10. What positives have come from the upcoming changes?

11. What other concerns or thoughts do you have in regards to employee engagement and/or the upcoming FLSA changes?

Demographic Questions:

12. What industry do you provide HR services to?

13. How many do expect to be impacted by FLSA?

14. How many people are on your HR team?

15. How many people/employees does your HR team support?

16. Would you like a copy of the final report emailed to you? 